\title{
Secuencia didáctica para el favorecimiento de la Competencia Lectora en Escuela Nueva
}

Marilse Patiño Hernández * Liliana María Tuta López***

Artículo de investigación

Fecha de Recepción: 1 noviembre 2017.

Fecha de Aprobación: 30 abril 2018.

\section{RESUMEN}

En escuela nueva se trabaja con guías de aprendizaje, este material es la herramienta que el Ministerio de Educación Nacional validó con los lineamientos curriculares, los estándares y derechos básicos de aprendizaje para fortalecer los saberes de niños y niñas del área rural. Teniendo en cuenta lo anterior las cartillas se encuentran desactualizadas, lo que ha limitado el desarrollo de la competencia lectora para el avance del aprendizaje, dado que no permite que los estudiantes identifiquen los diferentes elementos intrínsecos dentro de un texto que conllevan a su interpretación y a su vez mejoren el proceso escolar obteniendo altos niveles de desempeño. Esto se evidencia en las sedes rurales del municipio de Floresta que manejan el modelo educativo escuela nueva con los resultados de las pruebas saber, lo cual ha determinado la revisión de las guías de aprendizaje que se vienen trabajando. De esta observación y análisis parte la implementación de una estrategia metodológica que consiste en la elaboración y aplicación de secuencias didácticas, no con el fin de desnaturalizar o desplazar las guías de aprendizaje, sino con la intención de favorecer el desarrollo de la competencia lectora, utilizando diversas actividades lúdicas y significativas, que a su vez complementen las cartillas con las que se cuentan en ellas.

Palabras Claves: Escuela Nueva, Competencia Lectora, Secuencia Didáctica. *marilseph@gmail.com

**1imatulo@gmail.com

Institución Educativa

Héctor Julio Rangel

Quintero - Floresta

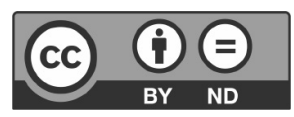




\section{Introducción}

El programa "Escuela Nueva" se desarrolla en las escuelas multigrado rurales que cuentan con población muy dispersa y un solo docente. Donde el maestro es un facilitador dado que quien en este modelo asume el rol de orientador es una guía didáctica o de autoaprendizaje, pero es el estudiante quien construye sus propios conocimientos. $\mathrm{Su}$ metodología, pedagogía activa permite que las actividades se complementen con las vivencias de los educandos y el contexto; de ahí que los niños estudian en pequeños grupos utilizando las guías de aprendizaje, las cuales son entregadas por el estado. En muchas instituciones este material no ha sido actualizado con las directrices del Ministerio de Educación Nacional (MEN), lo que ha limitado el desarrollo de la competencia lectora para el avance de su aprendizaje, que no solo permite que los estudiantes identifiquen la idea principal de un texto sino los diferentes elementos inmersos que conllevan a su interpretación y a su vez mejoren su aprendizaje en todo el proceso escolar obteniendo altos niveles de desempeño.

Esta premisa ha producido en los estudiantes un desinterés y apatía en la realización de las actividades que se proponen ya que las guías de aprendizaje no le permiten relacionarse con el contexto real al que se tienen que enfrentar. Después de un análisis a las diferentes cartillas de todos los grados se ha deducido que: no se cuentan con guías de contenidos y trabajo para el nivel de preescolar; las guías de grado primero enfrentan de forma inmediata al niño con el texto escrito, sin tener en cuenta que es el curso donde se va a aprender a leer y escribir, olvidando que se requiere un proceso para la adquisición de la lectura y por tanto va en contra de los principios del preescolar que se maneja en las instituciones oficiales donde el niño se integra, participa y juega; en los siguientes grados de primaria las guías presentan actividades repetitivas, los temas no profundizan en las temáticas y aspectos que estos deben contener. Para este sentido se aclara que en el año 2012 se realizó una revisión a las guías de escuela nueva, según el artículo lectura y escritura en la universidad. Esta revisión de actualización para las guías aún no ha llegado a algunas Sedes rurales, porque se cuenta con la edición del 2008 las cuales no tienen los Derechos básicos de aprendizaje y tampoco presentan actividades que permitan la formación de estudiantes competentes, para un buen desempeño en las pruebas saber, ya que estas muestran un bajo nivel en la competencia lectora.

Es cierto que en la institución se promueven proyectos transversales que incentivan la lectura siguiendo las orientaciones que el Ministerio de Educación Nacional ofrecey los docentes dentro del aula ejecutan las diferentes acciones para que estos se cumplan como son: hora de lectura, rincones de lectura, talleres de comprensión de textos, olimpiadas de comprensión de lectura entre otros; pero en la práctica estas actividades se convierten en mecánicas y formales. Donde el docente no utiliza las diversas estrategias 
existentes o no maneja los diferentes niveles de comprensión lectora, por tanto no se realiza los seguimientos, análisis y reflexiones pertinentes que retroalimenten y transformen dichas acciones generando unos resultados evidentes en la competencia lectora.

Por consiguiente, se realizó una revisión bibliográfica sobre los antecedentes en investigaciones de orden nacional e internacional que hicieran referencia y tuvieran aportes o avances relacionados con el tema, pero no se encontraron evidencias de que se hubiesen realizado con respecto a la implementación y el impacto de secuencias didácticas para fortalecer la competencia lectora en el modelo de escuela nueva.

Así pues, se busca dar respuesta a la pregunta ¿De qué manera la secuencia didáctica como estrategia metodológica puede favorecer el desarrollo de la competencia lectora en las sedes rurales? y se plantea una estrategia metodológica que consiste en la elaboración y aplicación de secuencias didácticas sin desconocer el uso de las guías de aprendizaje de escuela nueva para el desarrollo de la competencia lectora. Se parte de la acción de identificar el nivel de competencia lectora en que se encuentran los estudiantes, posteriormente se analiza la estructura didáctica de las guías de aprendizaje de escuela nueva para indagar las debilidades y fortalezas que estas presentan, luego se aplica la secuencia didáctica en el área de lenguaje para el desarrollo de la competencia lectora y por último se socializa y evalúa el impacto de esta como apoyo de las guías de aprendizaje de Lenguaje en Escuela Nueva.

\section{Sustentos teóricos}

Con el propósito de obtener una visión más amplia sobre el objeto de estudio: secuencia didáctica para el favorecimiento de la competencia lectora. Se realizó una revisión bibliográfica, donde se encontraron los estudios que se describen a continuación.

En referencia a la competencia lectora, varios trabajos de investigación han brindado innumerables aportes que apuntan hacia la forma en que se logra la comprensión de un texto, como "estrategias de comprensión lectora: enseñanza y evaluación en educación primaria” de Calixto y Salmerón (2012) quienes propician algunas estrategias de aprendizaje que facilitan el proceso lector y así mismo ofrecen unos programas de intervención, de técnicas e instrumentos de evaluación; por otra parte M.Jesús Pérez Zorrilla (2005) "evaluación de la comprensión lectora: dificultades y limitaciones" aborda esta temática desde lo práctico: el desarrollo de la evaluación de la comprensión lectora, además nos orienta sobre los diferentes niveles que se deben tener en cuenta para esta, así como el tipo de texto que se usa para el análisis de la comprensión.

En secuencia didáctica, se encuentra la investigación de César Hernando Agudelo Giraldo "secuencia didáctica para la comprensión lectora desde la perspectiva de Teun Van Dijk aplicada a estudiantes de $6-2^{\circ}$ de la institución educativa Byron Gaviria de la ciudad
M.Jesús Pérez Zorrilla (2005) "evaluación de la comprensión lectora: dificultades y limitaciones" aborda esta temática desde lo práctico: el desarrollo de la evaluación de la comprensión lectora, además nos orienta sobre los diferentes niveles que se deben tener en cuenta para esta, así como el tipo de texto que se usa para el análisis de la comprensión. 
de Pereira” (Byron \& Pereira, 2014) quien realiza la sistematización de una secuencia didáctica con una experiencia pedagógica en el área de lengua castellana. Al igual se encuentra otra investigación de Sánchez, María de los Milagros "implementación de una secuencia didáctica en la enseñanza de la lectura y escritura en contextos de estudio en la formación docente inicial” (Sánchez, 2012) en donde se plantea focalizar la atención en las situaciones de lectura y escritura que se desarrollan en la aulas de formación docente y sobre las prácticas reales que se hacen en este ámbito académico. Aún falta agregar que Ángel Díaz Barriga realizó un trabajo importante al respecto: secuencias de aprendizaje. $¿$ ¿Un problema del enfoque de competencias o un reencuentro con perspectivas didácticas? allí se cuestiona las orientaciones que se le dan a los docentes para trabajar con el enfoque de competencias, "no existe una forma o estrategia específica para trabajar en el aula desde el enfoque de competencias. A partir de ello se fundamenta como un enfoque didáctico permite la construcción de secuencias didácticas" (Barriga, 2013).

Finalmentey con alusión a escuela nueva, Víctor Manuel Gómez C. (1993) en su trabajo de investigación "visión crítica sobre la escuela nueva en Colombia", hace un análisis al modelo escuela nueva exponiendo sus debilidades y fortalezas de la implementación en Colombia. De otra parte Imbachi Polo Mauro Andrés, en su artículo (2012) "La escuela nueva y las competencias lectoras desarrolladas en el área de lengua castellana" ilustra detalladamente la forma en que se desarrolla la metodología y el uso de las guías de aprendizaje en el área de matemáticas y español las cuales requieren revisión para fortalecer la enseñanza lecto-escritora.

La Escuela Nueva es un modelo de escuela rural que está vigente en Colombia desde 1975 y que ofrece cinco años de básica primaria con uno o dos maestros facilitadores. Como dice Gómez (1993), el propósito es ofrecer toda la primaria en las zonas rurales, donde la educación sea dinámica y significativa, orientada por cartillas y promoción flexible, que forme al estudiante en valores cívicos y sociales mediante un esquema de gobierno escolar. Con este modelo de escuela, en Colombia se ha buscado mejorar la importancia y relevancia de la educación rural aumentando al mismo tiempo la cobertura.

Según Gómez (1993), la problemática educativa de la Escuela Nueva en Colombia puede sintetizarse en dos dimensiones fundamentales: dimensión cuantitativa la cual aborda la baja cobertura, alta deserción, baja eficiencia interna, y alto grado de desigualdad en estos indicadores respecto a la educación primaria en áreas urbanas y la dimensión cualitativa que muestra una educación pasiva, memorística; contenidos inadecuados y desadaptados a condiciones y necesidades rurales; ausencia de materiales didácticos; horarios rígidos e inadecuados para las condiciones de trabajo rural; desvinculación con la comunidad, poco aporte a su desarrollo, etc. 
Sobre esta última dimensión se plantea hacer una intervención desde el parámetro evaluativo con el fin de producir innovación sin perder de vista los objetivos de la escuela nueva, entre otros: 1) promoción del aprendizaje activo y reflexivo, 2) desarrollo de habilidades de pensamiento, de destrezas investigativas, creativas, analíticas y explicativas, 3) formación de valores (MEN, 2009).
De acuerdo con Gómez (1993), la estructura de la Escuela Nueva está constituida por cuatro componentes estratégicos: 1) capacitación y seguimiento, 2) currículo basado en guías didácticas o de autoaprendizaje, 3) administración basada en monitoreo del Ministerio de Educación, 4) comunidad y escuela. En particular el segundo componente estratégico está configurado así:

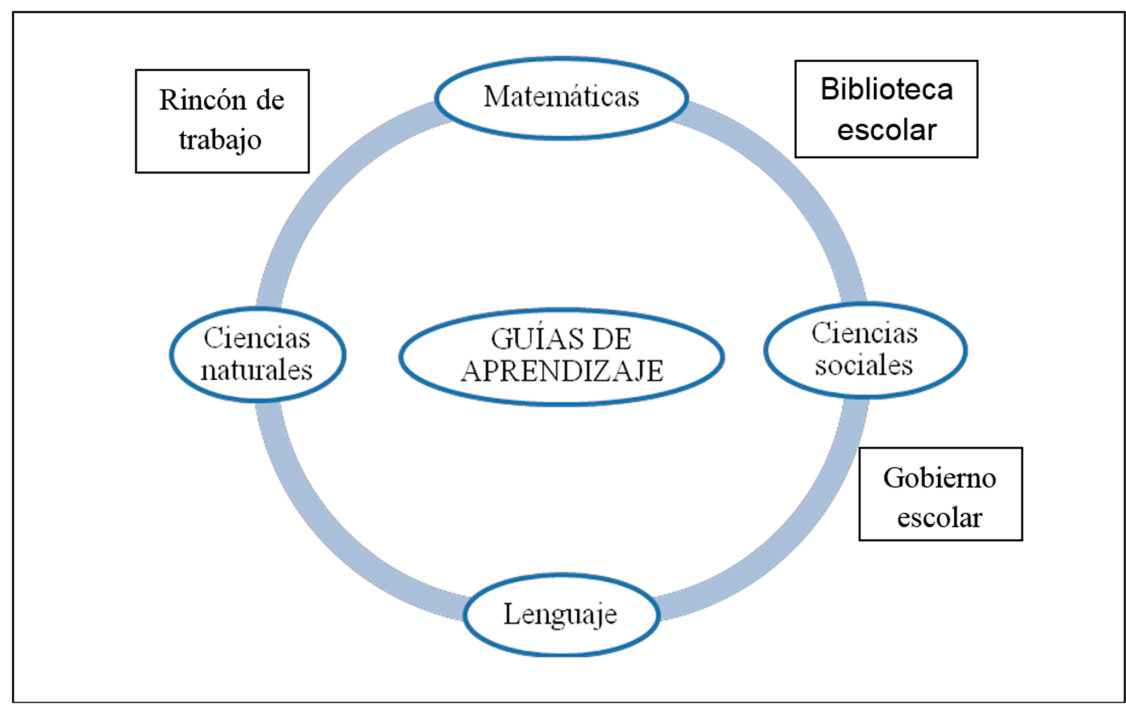

Figura 1. Guías de aprendizaje y otros materiales que complementan, apoyan y amplían el aprendizaje activo. Elaborado por autoras.

Como se puede observar, la guía didáctica o de autoaprendizaje es el material pedagógico central en la estructura de la escuela nueva. El texto guía en este modelo no sólo determina los contenidos de aprendizaje sino las actividades que el estudiante debe realizar para efectos de su enseñanza. Así mismo, como lo plantea Gómez (1993): una de las principales carencias y debilidades del programa escuela nueva en Colombia se deriva del inadecuado proceso de planeación, producción y evaluación de las Guías y otros materiales de aprendizaje, los cuales no son adaptados a la realidad y necesidades del estudiante rural, donde los maestros relacionan la pedagogía con la comunidad.

Lo anterior plantea la necesidad de innovación en términos del material didáctico y metodológico de la escuela nueva que promueva el desarrollo de habilidades para mejorar los diferentes niveles de competencia lectora. 
Teniendo en cuenta que por competencia lectora se entiende aquella habilidad para comprender y utilizar con sentido las formas lingüísticas de una cultura por parte de un individuo; esto significa que la competencia lectora está en directa relación con el aprendizaje (Solé, 2012). Por otra parte, la Organización para la Cooperación y el Desarrollo Económicos (OCDE), que realiza las pruebas PISA internacionales, plantea que la comprensión lectora consiste en "la capacidad de comprender, utilizar, reflexionar e interesarse por los textos escritos para alcanzar los propios objetivos, desarrollar el conocimiento y potencial personales, y participar en la sociedad (OCDE, 2009, p.14).

En general hoy, desde la experiencia pedagógica, "Se acepta que comprender implica conocer y saber utilizar de manera autónoma un conjunto de estrategias cognitivas y metacognitivas que permiten procesar los textos de manera diversa, en función de los objetivos que orientan la actividad de lector" (Solé, 2012, p.49), por tanto el desconocer las estrategias y el momento oportuno de aplicación de las herramientas que desarrollan estos procesos por parte del docente, se hace dificil que la competencia lectora se convierta en una gran base para la socialización de los contenidos aprendidos desarrollando una comunicación oral y escrita de interpretación de la realidad para construir y organizar el conocimiento y asimismo la conducta.

Según Pérez (2005) existen los siguientes niveles de competencia lectora:

Figura 2. Niveles de competencia lectora propuesta por Pérez.

Elaborado por autoras.

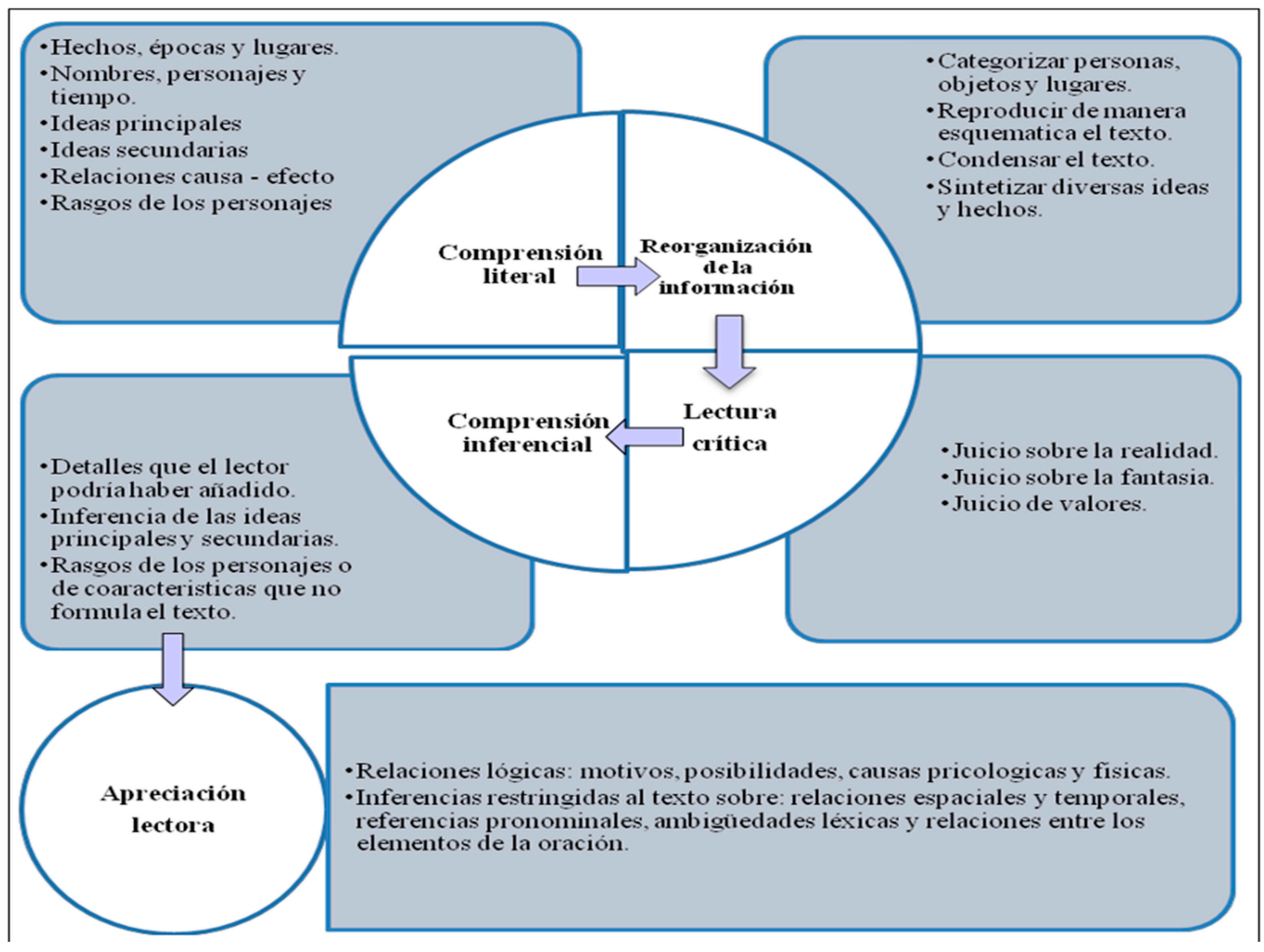




\section{Secuencia didáctica}

La secuencia didáctica entendida como alternativa didáctica permite al docente establecer un ambiente de aprendizaje significativo y que permite a sus estudiantes por medio de actividades secuenciadas, gestar su propio aprendizaje. Para Díaz Barriga la secuencia didáctica es la organización de actividades de aprendizaje que se realizan con los estudiantes para desarrollar un aprendizaje significativo; por tanto como él mismo lo advierte no es el ejercicio de llenar espacios en blanco sino el acertado y pertinente conocimiento de la asignatura por parte del docente así como su experiencia y la habilidad de proponer y planear actividades que conlleven a un aprendizaje más efectivo en sus estudiantes.

Esto conlleva a entender que permite al docente adaptar los contenidos a la realidad, que parte de un proceso reflexivo entre estudiante y docente; a su vez facilita la flexibilidad en el desarrollo práctico hacia un objetivo claro sin hacer improvisación en el planteamiento de las mismas y la integración de contenidos en forma interdisciplinar. La secuencia didáctica también promueve valores, actitudes de cooperación, actividades lúdicas y trabajo en grupo, lo cual, permite integrarla con las guías de aprendizaje que se tienen en escuela nueva.

Dentro de la diversidad de propuestas que se tejen alrededor de la forma de elaborar una secuencia didáctica, Díaz Barriga también propone una guía que puede ser tomada como referencia para la elaboración de la misma, aunque no se limita a su modelo sino que deja al criterio del docente los elementos que puedan utilizar sin desconocer aquellos que se creían eran más relevantes. Tales elementos hacen referencia entre otros a los contenidos, objetivos, duración, actividades a realizar.

El siguiente es un formato de secuencia didáctica que fortalece la guía de aprendizaje:

\begin{tabular}{|c|c|}
\hline \multicolumn{2}{|l|}{ Nombre y apellidos del docente } \\
\hline \multicolumn{2}{|l|}{ Institución Educativa } \\
\hline \multicolumn{2}{|l|}{ Sede } \\
\hline \multicolumn{2}{|l|}{ Municipio } \\
\hline \multicolumn{2}{|l|}{ Departamento } \\
\hline \multicolumn{2}{|l|}{ 1. $\quad$ DATOS GENERALES } \\
\hline Título de la secuencia didáctica: & Secuencia Didáctica No.: \\
\hline Área de conocimiento: & Tema: \\
\hline \multirow{2}{*}{ Grado: } & Duración: \\
\hline & No. de Sesiones: \\
\hline \multicolumn{2}{|c|}{ Descripción de la Secuencia Didáctica: } \\
\hline \multicolumn{2}{|c|}{ 2. $\quad$ LOGROS, ESTÁNDARES Y COMPETENCIAS } \\
\hline Logros: & \\
\hline
\end{tabular}




\begin{tabular}{|c|c|c|}
\hline \multicolumn{3}{|c|}{ Contenidos a desarrollar } \\
\hline & ompetencias del MEI & Estándares: \\
\hline \multicolumn{3}{|c|}{ Qué se necesita para trabajar con los estudiantes: } \\
\hline \multicolumn{3}{|c|}{ 3. METODOLOGÍA } \\
\hline & Fases & Actividades \\
\hline \multicolumn{3}{|c|}{ ¡Preguntémonos! } \\
\hline \multicolumn{3}{|c|}{ ¡Exploremos! } \\
\hline \multicolumn{3}{|c|}{ ¡Produzcamos! } \\
\hline \multicolumn{3}{|c|}{ ¡Apliquemos! } \\
\hline \multicolumn{3}{|c|}{ Conclusiones laborado } \\
\hline \multicolumn{3}{|c|}{ 4. RECURSOS } \\
\hline \multirow{2}{*}{\multicolumn{3}{|c|}{\begin{tabular}{l|l} 
Nombre del recurso & Descripción del recurso \\
$5 . \quad$ EVALUACIÓN. INSTRUMENTOS Y PRODUCTOS ASOCIADOS
\end{tabular}}} \\
\hline & & \\
\hline \multicolumn{3}{|c|}{ 6. $\quad$ BIBLIOGRAFÍA } \\
\hline
\end{tabular}

Figura 3. Formato secuencia didáctica. Elaborado por autoras.

En la estructura de la secuencia didáctica se integran varios aspectos, pero los más importantes son las actividades que sean de manera ordenada partiendo de las ideas previas del estudiante hasta la creación del conocimiento, donde los trabajos, los productos o tareas son elementos de evaluación, en sus tres dimensiones diagnóstica, formativa y sumativa.

\section{Aspectos Metodológicos}

La presente investigación acción es de enfoque cualitativo, ya que permite indagar, preguntar, profundizar $\mathrm{y}$ deducir a partir de las observaciones y análisis dentro de la práctica en el aula de clases y las distintas interrelaciones que se presentan entre los actores educativos. Por otro lado,

Le Compte (1995, p. 29), indica que la investigación cualitativa es aquella que realiza "descripciones a partir de observaciones que adoptan las formas de entrevistas, narraciones, notas de campo, grabaciones, transcripciones de audio y videocasetes, registros, escritos de todo tipo, [...]". Para la aplicación, los instrumentos de información $\mathrm{y}$ recolección de datos son la observación, el diario de campo, análisis de videos y transcripciones de audio.

Por lo tanto la investigación se desarrolla, según las fases propuestas por Elliott (2005): 


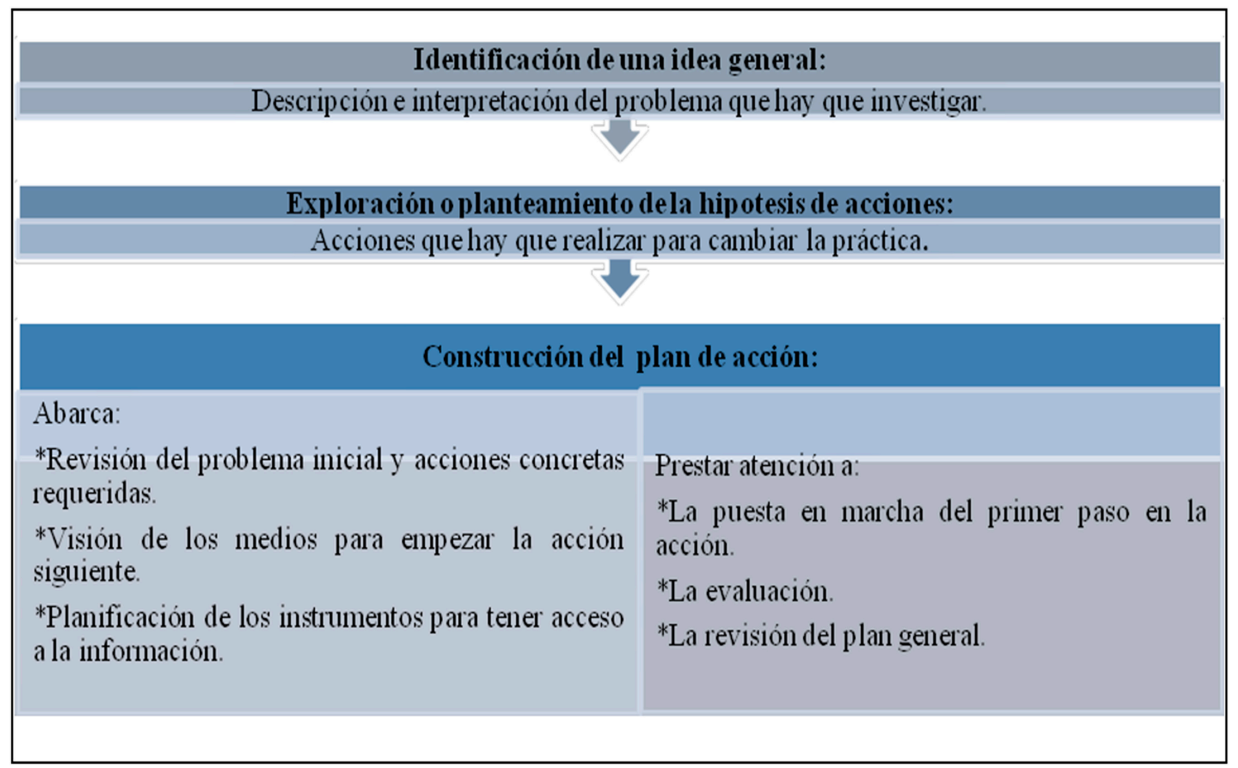

Figura 4. Fases de la investigación acción propuesta por Elliott. Elaborado por autoras.

Teniendo en cuenta las fases anteriormente mencionadas, en primer lugar se reconoce el problema que se hace evidente en los bajos resultados obtenidos en las pruebas saber de los estudiantes de primaria de las sedes rurales en el municipio de Floresta, después de un análisis se encuentra que a ellos se les dificulta evaluar la información explícita o implícita de un enunciado, no identifican las relaciones y diferencias entre textos de diferentes formatos lo cual no les permite utilizar estrategias que les faciliten la comprensión y la organización de ideas.

Es necesario recalcar que la población está constituida por los estudiantes del grado tercero de primaria de las sedes rurales de Tobasia y Tocavita del municipio de Floresta. Sus edades fluctúan entre entre los 8 y 10 años. $\mathrm{Su}$ entorno social está enmarcado en el desarrollo de actividades propias del campo como lo son la siembra y cosecha, el ordeño, recolección de leña y ayuda en las labores del hogar. Su nivel económico se encuentra en el estrato uno, las familias están en su mayoría constituidas por los dos padres, otros solo por mamá o papá, pero sus aportes a las labores académicas son mínimas, ya que algunos solo cuentan con un nivel básico de estudio. Los niños de la sede Tobasia cuentan con acceso a televisión e internet con el programa kiosko vive digital; en la sede Tocavita el acceso a internet es casi nulo y la señal de televisión es fluctuante lo cual los pone en desventaja frente a otros sectores educativos del municipio.

Posteriormente, se realiza una actividad diagnóstica para identificar el nivel de competencia lectora en que se encuentran los niños; donde los estudiantes organizan una secuencia de imágenes y construyen un relato oral, en seguida escriben una 
Los perfiles se usan para describir el trabajo del estudiante en una determinada situación y tiempo, donde los resultados se comparan a medida que avanza la investigación para ver la evolución del mismo. Los documentos como el planeador y mallas curriculares, los cuales aportan información útil sobre los contenidos y actividades que se realizan en el aula y pueden ser sometidas a adaptaciones de acuerdo a lo que se está investigando. narración a partir de lo trabajado. Luego se plantean las posibles causas que han venido generando la deficiencia en la competencia lectora, la cual permite aducir que las guías de escuela nueva están desactualizadas para las directrices del MEN y los avances tecnológicos y sociales que se han suscitado, además sus contenidos y didáctica no asumen la realidad del niño rural, por tanto no son apropiadas para generar en el estudiante actitudes que fomenten la competencia lectora.

Por todo lo anteriormente expuesto las secuencias didácticas se formulan como estrategia metodológica viable para propiciar soluciones de fondo al problema, ya que estas por su flexibilidad, dinamización y organización de sus actividades con orden y ritmo, permiten integrar las diferentes áreas, realizar ajustes y reflexiones a las propuestas que se plantean en su aplicación.

De acuerdo a lo que se ha planteado es necesario conocer los instrumentos de recolección y técnicas de análisis de la información, estos son propuestos por Elliott (1993) de la siguiente manera: diario de campo, documentos, perfiles, datos fotográficos, triangulación, grabaciones en cintas magnetofónicas o en vídeo; los cuales permiten la organización y secuenciación del trabajo que se realiza durante el proceso de investigación.

Así pues, el diario de campo facilita el registro de las diferentes situaciones comportamentales, sociales, emocionales y de aptitud que se evidencian durante el desarrollo de las actividades en el aula con respecto a la temática a trabajar. Esto se aplica para comparar, reconstruir los hechos y relacionarlos con lo encontrado y su evolución. Los perfiles se usan para describir el trabajo del estudiante en una determinada situación y tiempo, donde los resultados se comparan a medida que avanza la investigación para ver la evolución del mismo. Los documentos como el planeador y mallas curriculares, los cuales aportan información útil sobre los contenidos y actividades que se realizan en el aula y pueden ser sometidas a adaptaciones de acuerdo a lo que se está investigando.

También, los datos fotográficos que facilitan y son evidencia fehaciente de las actividades que realiza el estudiante en el aula y las interacciones que se dan. Las grabaciones en cinta magnetofónicas, en vídeo y transcripciones permiten registrar una situación particular $\mathrm{y}$ real que puede ser transcrita para su interpretación. La triangulación reúne las evidencias y observaciones desde varias perspectivas que al ser analizadas genera contrastación y verifica los puntos de convergencia y divergencia útiles para el posterior concepto de la situación estudiada.

Estos instrumentos de recolección se aplican en un momento en particular con la finalidad de buscar información sobre el impacto de la secuencia didáctica en el área de lenguaje a través del desarrollo de las actividades que se realizan al interior del aula de escuela nueva con la ejecución de las guías de aprendizaje, para así fortalecer la competencia lectora en los educandos y mejorar el nivel de desempeño en las pruebas externas. 


\section{Resultados fase diagnóstica}

De este proceso se sustraen los siguientes aspectos observados:

\begin{tabular}{|c|c|}
\hline Sede Tocavita & Sede Tobasia \\
\hline $\begin{array}{l}\text { Las niñas en la sede Tocavita estuvieron a la expectativa } \\
\text { a desarrollar el trabajo propuesto, al organizar las } \\
\text { imágenes no tuvieron en cuenta los diferentes detalles } \\
\text { que ayudaban a identificar el posible orden lógico, el } \\
\text { vocabulario al expresar sus ideas no es muy rico en } \\
\text { palabras y conectores, al momento de la escritura no } \\
\text { tuvieron en cuenta ordenar sus ideas para relatar con } \\
\text { coherencia la historia que habían planteado en un } \\
\text { principio, no hacen uso de los signos de puntuación, } \\
\text { no tienen en cuenta la información completa para el } \\
\text { desarrollo de una tarea asignada. } \\
\text { También se evidencia que la información dada } \\
\text { por la docente no se entendió desde un principio } \\
\text { en forma acertada y sin embargo no se verificó su } \\
\text { comprensión, se utilizó una misma orden o tarea } \\
\text { para los distintos grados. }\end{array}$ & $\begin{array}{l}\text { En esta clase los estudiantes se sintieron alegres } \\
\text { en el momento de entregarles las imágenes, se } \\
\text { observa que muchos de ellos no identifican } \\
\text { los elementos de la narración (lugar, tiempo, } \\
\text { personajes y acciones), aunque sabían su } \\
\text { significado. } \\
\text { En el instante de redactar el cuento no llevaban } \\
\text { la secuencia, escribía lo que observaba en las } \\
\text { imágenes. } \\
\text { Cuando comenzaron a leer algunos lo hicieron } \\
\text { en forma silábica y no entendían lo que había } \\
\text { escrito. Falto orientación de la docente al } \\
\text { momento de escribir el cuento para que ellos } \\
\text { llevaran una secuencia, porque el gusto para } \\
\text { llevar a cabo una actividad necesita de interés } \\
\text { y motivación. }\end{array}$ \\
\hline
\end{tabular}

Luego de la comparación se evidencia que: poseen conocimientos pero les es difícil su aplicación, falta reconocimiento de los elementos del cuento, como son personajes, lugar, tiempo y acciones, se les dificulta organizar imágenes para construir el cuento y llevar una secuencia, olvidan la información después de haber leído, aunque en este aspecto no se deduce que no hayan comprendido el texto grafico porque no necesariamente converge al mismo tiempo la capacidad expresiva, algunos leen silábicamente, al momento de escribir omiten algunas letras, tienen que leer varias veces una pregunta para darle una respuesta, presentan una lectura lenta e insegura y muestran desinterés por leer la información completa.

Esto demuestra que los estudiantes se encuentran en un nivel literal, ya que algunos leen lento o rápidamente, sin ninguna comprensión que identifique lo leído, se ha tomado la lectura como algo obligatorio, sin finalidad educativa por sus carentes hábitos lectores en sus hogares porque son familias que muchas veces no cuentan con libros, que les permitan mejorar su aprendizaje en todos los procesos escolares. La oportunidad para leer únicamente se desarrolla dentro del aula utilizando las mismas guías.

Según la observación realizada a las guías de aprendizaje como elemento primordial en modelo educativo escuela nueva presenta algunas debilidades como lo son: la carencia de actividades didácticas que conlleven a un aprendizaje significativo y duradero, los temas no se encuentran relacionados con el contexto real de los 
estudiantes, las actividades propuestas son repetitivas lo que genera en el niño desmotivación en la realización de sus tareas y los conceptos temáticos son muy superficiales. Pero a su vez cabe resaltar que estas: permiten el trabajo en grupo donde los niños interactúan y generan comparación de saberes, fomentan $y$ fortalecen el autoaprendizaje, genera en el niño la responsabilidad por concluir las actividades propuestas, permite realizar adaptaciones por parte del docente, respeta el ritmo de aprendizaje de cada uno de los estudiantes y es una herramienta válida para el trabajo ya que para el docente se le facilita el desarrollo de las actividades en los diferentes grados.

Es así que por la des actualización de las cartillas no permite que el estudiante avance, desarrolle en ellos competencias lectoras e incentiven el aprender a aprender, a hacer, a comunicarse y a convivir en su contexto.

Ahora veamos, el docente por sus prácticas dentro del aula, también tiene influencia en el desarrollo de la competencia lectora y si él no ha desarrollado habilidades personales en este aspecto, difícilmente podría enseñar. Muchas de las acciones entonces se ciñen de acuerdo a las condiciones que se presentan y los recursos con los que se cuentan. En ocasiones las acciones que se toman van más encaminadas a lo procedimental, pero las que se realizan son similares entre los diferentes grados que se manejan, otro tópico que manifiesta entonces es que las actividades se dirigen a lo más elemental de comprensión en el nivel literal.

\section{Conclusiones}

La secuencia didáctica da autonomía al docente y establece un ambiente de aprendizaje significativo, con actividades estructuradas y secuenciadas que permitan al estudiante ser partícipe de su aprendizaje, esto conlleva a entender que el diseño de las mismas se hace teniendo conocimientos de la asignatura, al igual que los intereses y necesidades que se tienen en el entorno en que el niño vive. Por tanto y de esta manera no desconocen el uso de las guías de aprendizaje de escuela nueva, al contrario buscan complementar y fortalecer con acciones acertadas los procesos de enseñanza.

Es así que la aplicación de la secuencia didáctica en el área de lenguaje busca generar un impacto en el desarrollo de las actividades que se vienen realizando al interior del aula de escuela nueva con el desarrollo de las guías de aprendizaje, para fortalecer la competencia lectora en los educandos y mejorar el nivel de desempeño en las pruebas externas.

Además la competencia lectora se ha venido abordando en forma superficial sin que el docente asuma parte de su responsabilidad en el proceso. Ya que, es él, quien plantea las actividades que incentivan en el niño la interacción con los diferentes tipos de texto y así mismo generan relación entre estos $\mathrm{y}$ los significados de lo leído, por tanto se hace necesario reflexionar sobre la práctica que se realiza en el aula y que va dirigida al desarrollo de la misma porque esta se pueden desarrollar o inhibir. Es importante no olvidar también que el 
docente muchas veces se ve limitado por los escasos recursos materiales con los que cuenta para realizar dicho proceso sin embargo esto no es impedimento para desarrollar la actividad, porque se deben propiciar estrategias como la de secuencia didáctica para organizar acciones que no solo se queden en ejercicios mecánicos que conllevan a la comprensión literal básica sino que permita llegar a niveles donde se usen pensamientos más complejos de inferencia y de relación entre los conocimientos previos y lo leído, a este aspecto se agrega que el exceso de programas y contenidos curriculares que hacen parte de las diferentes áreas limitan los espacios que se pueden dedicar a la enseñanza de la competencia lectora.

Pero para el desarrollo de la competencia lectora se hace necesario no olvidar que para el modelo educativo de escuela nueva el elemento primordial en la enseñanza son las guías de aprendizaje, las cuales fueron diseñadas con instrucciones repetitivas y formales que no permiten modificaciones de fondo, son muy rígidas, lo que hace que el niño muestre apatía y pereza por realizar las tareas que allí se asignan. Las temáticas y contenidos que abordan no pasan de ser tratados superficialmente, no ahondan en actividades que fortalezcan nuevos conocimientos y desconocen la realidad que los niños menos favorecidos tienen.

Al finalizar la implementación de la secuencia didáctica como estrategia metodológica se espera que los estudiantes adquieran habilidades lectoras que le serán útil para la argumentación, interpretación y análisis de un texto, y a su vez fomentar el hábito por la lectura que lo llenara de gozo para utilizar la creatividad en la construcción de textos, el desarrollo de las pruebas saber y el mejoramiento de los procesos educativos en cada una de las etapas de su vida. Por otra parte supone un cambio de actitud y de continua indagación y búsqueda por parte del docente frente a la planeación y diseño de actividades que sean más didácticas y que propendan a realizar el desarrollo de la competencia lectora a los nivel inferencial y de crítica, de tal manera que esto conlleve a mejorar el aprendizaje en las diferentes áreas que también requieren de esta.

Sin embargo, el limitado tiempo para la aplicación de esta estrategia no permite ver hasta donde se puede llegar para conocer sus fortalezas y dificultades no solo en el proceso del desarrollo de la competencia lectora para evidenciar los avances y mejoras en la presentación de dichas pruebas, sino en los distintos escenarios en que el niño se debe desenvolver y demostrar que la adquisición de sus conocimientos son los esperados para ser un ciudadano competente.

Consciente de la necesidad de promover el amor por la lectura en todos los niveles y materias; para el mejoramiento de la calidad de la educación; es alegre compartir este compromiso con los estudiantes, porque es función imperativa de la labor docente a nivel primario generar estrategias que gradualmente ayuden al desarrollo de la competencia lectora.
Para el desarrollo de la
competencia lectora se hace
necesario no olvidar que
para el modelo educativo de
escuela nueva el elemento
primordial en la enseñanza
son las guías de aprendizaje,
las cuales fueron diseñadas
con instrucciones repetitivas
y formales que no permiten
modificaciones de fondo,
son muy rígidas 


\section{REFERENCIAS}

Elliott, J. (1993). El Cambio educativo desde la investigación-acción. Pedagogía. Manuales.

Gómez, M. (1993). Visión crítica sobre la Escuela Nueva en Colombia. Revista Educación Y Pedagogía Nos. 15, (1), 280-306.

Gutiérrez, C., \& Salmerón, H. (2012). Estrategias de comprensión lectora: Enseñanza y evaluación en educación primaria. Profesorado, Revista de Currículum Y Formación Del Profesorado, 16(1), 183-202.

MEN (2009). Manual de implementación de Escuela Nueva. Tomo 1. Recuperado de: http://www.mineducacion.gov.co/1759/articles340089_archivopdf_ orientaciones_pedagogicas_t omol.pdf

Organización para la Cooperación y el Desarrollo Económicos, OCDE (2009). Pisa 2009 Assessment Framework - Key Competencies in Reading, Mathematics and Science. París: ocde. Disponible en:_www.oecd.org/ dataoecd/11/40/44455820.pdf.

Sánchez, M. (2012). Implementación de una secuencia didáctica en la enseñanza de la lectura y escritura en contextos de estudio en la formación docente inicial. (Tesis de posgrado) Universidad Nacional de La Plata. Facultad de Humanidades y Ciencias de la Educación. Disponible en: http://www.memoria.fahce.unlp. edu.ar/tesis/te.747/te.747.pdf

Pérez, M. (2005). Evaluación de la comprensión lectora: dificultades y limitaciones. Revista de Educación. No. Extraordinario.

Solé, I. (2012). Competencia lectora y aprendizaje. Revista Iberoamericana de educación, (59). 